\section{Etnografia i eksperymenty artystyczne. O powstawaniu nowych pól poznawczych we współczesnej antropologii}

Tomasz Rakowski

TEKSTY DRUGIE 2017, NR 1, S. 91-110

DOI: 10.18318/td.2017.1.7
Praca powstała w ramach

projektu Narodowego

Centrum Nauki pt. „Wy-

zwania etnografii twórczej.

Wypracowanie naukowego warsztatu «badań

w działaniu», uchwytującego peryferyjne aktywności twórcze iłączącego perspektywę intensywnych badań antropologicznych z animacją kultury i projektami z zakresu sztuki współczesnej" (NCN 2012/05/D/ $\mathrm{HS} 2 / 03639)$, prowadzonego w zespole: Ewa Chomicka, Dorota Ogrodzka, Tomasz Rakowski, Ewa Rossal.

Tomasz Rakowski etnolog, antropolog kultury, kulturoznawca, lekarz. Adiunkt w Instytucie Etnologii i Antropologii Kulturowej UW, współpracuje z Instytutem Kultury Polskiej UW. Zajmuje się antropologicznymi badaniami ubóstwa, badaniami oddolnych procesów rozwojowych, antropologią sztuki współczesnej i partycypacyjnej, etnograficznie zorientowaną animacją kultury oraz najnowszą metodologią badań kulturowych. Autor książki Łowcy, zbieracze, praktycy niemocy. Etnografia człowieka zdegradowanego (2009). 
kulturowych, wzbogacania języków opisu, przełamywania poststrukturalistycznych pułapek, a jednocześnie też - pułapek zwrotu praktycznego, które pojawiły się po latach dominacji interpretacji postsemiotycznych i poststrukturalnych. W ten sposób chcę zarysować możliwą drogę antropologii - jej swoisty "cykl rozwojowy” idący wzdłuż tzw. zwrotu ontologicznego i zwrotu działaniowego, przy czym szczególnie istotna będzie tu pozycja eksperymentu artystycznego jako sposobu wytwarzania nowej sceny poznania i sięgania w stronę nieprzewidywalnych sytuacji badawczych.

\section{Powrót do Writing Culture i pójście dalej, nieco inną drogą}

Można założyć, na potrzeby rekonstrukcji, że historia zaczyna się w latach 80. wraz z falą eksperymentów postmodernistycznych w antropologii i, co jeszcze bardziej istotne - eksperymentów w antropologicznych badaniach terenowych. To wtedy pojawiła się swoista kulminacja świadomości literackości opisu antropologicznego i całej gry toczącej się na poziomie tworzenia korespondujących ze sobą tekstów, metafor, wyobrażeń - w pracy, gabinecie czy namiocie etnografia dało się więc słyszeć coraz głośniejsze i coraz bardziej natarczywe „skrzypienie wielu innych, antropologicznych piór"'. Rozmontowanie i dekonstrukcja zabiegów pisarskich, wydobywanie w nich pól władzy i całego systemu produkcji wiedzy dały efekt w postaci coraz silniejszego poczucia arbitralności, pośredniości, polityczności i literackiej przygodności (poetyce) wiedzy terenowej. Ten „zwrot pisarski”2 zatrzymał jednak machinę metodologiczną na kilka lat, przynajmniej tych po publikacji Writing Culture ${ }^{3}$, a następnie znów pojawiły się nowe zupełnie drogi - wszystkie wynikały jednak z tej krytycznej perspektywy, ujęcia kultury jako rzeczywistości czytanej i pisanej zarazem.

Jest to na swój sposób pierwszy ważny moment, kiedy sięgnięto tam, gdzie powstaje opisywana rzeczywistość. Gmach tej wiedzy, wiedzy antropologicznej, został bowiem wzniesiony na sztuce opisu kulturowego, ale opisu bardzo specyficznego. Zawiera on w sobie bowiem dziedzictwo tekstowego wytwarzania rzeczywistości i czegoś co, można by nazwać pierwotną tekstualizacją

1 J. Clifford Kłopoty z kulturq. Dwudziestowieczna etnografia, literatura i sztuka, przeł. E. Dżurak i in., KR, Warszawa 2000, s. 34.

2 Zob. B. Scholte The Literary Turn in Contemporary Anthropology , "Critique of Anthropology" 1987 $7(1)$, s. 33-47.

3 Zob. J. Clifford, G. Marcus (eds.) Writing Culture. The Poetics and Politics of Ethnography, University of California Press, Berkeley-Los Angeles-London 1986. 
i jednocześnie semiotyzacją. Jest to oczywiście właśnie ów paradygmat „czytania kultury" i zwrot ku lekturze kulturowych znaczeń zbudowanej przez Clifforda Geertza ${ }^{4}$, a z czasem metafory czytania, tłumaczenia i pisania kultury pojawiły się ponownie po serii seminariów w Santa Fe w 1984 roku i zaczęły z wielką siłą oddziaływać, tworząc nowe, postsemiotyczne ramy antropologii kulturowej. U źródła jest to jednak zwrot w stronę rozumienia relacji z doświadczanej realności kultury jako „odczytywania”, jako gęstego opisu steoretyzowanego przez Geertza. James Clifford przedstawia ten proces następująco: $\mathrm{z}$ dyskursu czy wydarzenia powstaje tekst, a następnie jest on odczytywany w kontekście innych, zsemiotyzowanych już fragmentów wiedzy z terenu. „Nie zapisane zachowania - pisze - mowa, wierzenia, tradycja ustna i rytuał zostają oznaczone jako korpus, potencjalnie znaczący całokształt, wyodrębniony z bezpośredniej dziejącej się i płynnej substancji”’. I nieco dalej: „Zapisane w postaci tekstu rytuał czy wydarzenie nie są już blisko związane z tworzącymi je konkretnymi aktorami", i tu można dodać, że nie są już blisko też z tworzącymi je działaniami i aktywnymi intencjami społecznymi. Widać tu, że Geertz, zanim jeszcze wprowadzi owe wyodrębnione dane w kontekst kulturowy, utekstawia wcześniej to, co pierwotnie nietekstowe ${ }^{6}$.

Jednocześnie to już wtedy inni badacze, doświadczeni w pracy terenowej, Michael Jackson ${ }^{7}$, Paul Stoller ${ }^{8}$, także Thomas Csordas', piszą, że właściwie w antropologii nie tyle podążamy ku badaniom utekstowionej rzeczywistości,

4 Zob. C. Geertz Thick Description: Toward an Interpretative Theory of Culture, w: tegoż The Interpretation of Cultures, Basic Books, New York 1973.

5 J. Clifford Kłopoty z kulturq̨. Dwudziestowieczna..., s. 47-48.

6 Geertz korzysta tutaj z precyzyjnych rozważań Paula Ricœura o działaniu znaczącym rozważanym jako tekst. W pracy tej Ricœur pokazuje, że to co zostaje z wydarzenia dyskursu czy z działania, to właśnie to, co się utrwala, co zostaje w mówieniu powiedziane albo to, co zostaje w działaniu zrobione. A zatem tu, w tym miejscu pojawia się moment uchwycenia nietekstowej rzeczywistości jako znaczącej, zorganizowanej w tekst, w której kultura może być "odczytywana". Zob. P. Ricœur Model tekstu. Działanie znaczące rozważane jako tekst, przeł. ). Falkowska, "Pamiętnik Literacki” 1984 Z. 2.

7 M. Jackson Path Towards a Clearing. Radical Empiricism and Ethnographic Inquiry, Bloomington, 1989.

8 P. Stoller The Taste of Ethnographic Things. The Senses in Anthropology, Philadelphia 1989, tegoż Sensous Scholarship, Philadelphia 1997.

9 T. Csordas Introduction: The Body as Representation an Being-in-the World In Embodiment and Experience. The Existential Ground of Culture and Self, ed. by T. Csordas, Cambridge 2001; tegoż Embodiment and Cultural Phenomenology, w: Perspectives on Embodiment. The Intersection of Nature and Culture, ed. by G. Weiss, H.F. Haber, London-New York 1999. 
ile że jest to raczej proces rozumienia zachowań społecznych wykuwających się w idiomach "ucieleśnionego bycia w świecie”, w sferze codziennych aktywności - i to wtedy też można pokazać, że zapis rzeczywistości antropologicznej może zostać wydźwignięty na poziom metodologicznej samoświadomości. Jak to może wyglądać? Odwołam się tutaj do własnych doświadczeń badawczych - są to moje niedawne badania we współczesnej Mongolii poświęcone powstawaniu nowego pokolenia mongolskich kupców-biznesmenów, dzieci pasterzy, ale też odruchowych społeczników i aktywistów. W ich nieformalnym współdziałaniu ukazuje się to, co bardzo lokalne, mongolskie, idiomatyczne: w badaniach okazuje się, że to za ich sprawą organizowane są i fundowane w ich rodzinnym mieście, w „rodzinnej ojczyźnie” (nutag) ceremonie ofiarne tachiłga, gromadzące lokalną społeczność, organizują wręcz całe święto (naadam), z wyścigami koni, zapasami, koncertami i ceremoniami. Do rodzinnej ziemi przybywa wtedy ze stolicy kolumna przyozdobionych samochodów, Toyot Land Cruiserów, wypełnionych ciasno biznesmenami i ich rodzinami - wcześniej jadą w swych samochodach całą grupą przez Mongolię, ponad dobę, zatrzymując się, pijąc odrobinę wódki z ozdobnych czarek, błogosławiąc. Biznesmeni, ich rodziny, przyjaciele, spotykają się potem, już w rodzinnym miasteczku Bułgan, na obchodach i celebracjach, na wyścigach konnych, gdzie zebrani w kręgach kosztują pieczonego świstaka i wznoszą toasty. Następnego dnia, od rana objeżdżają kolejne święte góry, jadą szybko dużą grupą Toyot, wspinają się w kilkadziesiąt osób na poszczególne święte szczyty, tam sypią ryż, ziarno, kropią mlekiem, wódką, koniakiem. Łączy się to jednak też z wymiarem kosmologicznym - z budowaniem, poprzez skomplikowaną architekturę więzi społecznej, gromadności „siły powodzenia” i wyposażenia w „siłę życiową"10 , a to znów związane jest ze sprytem, siłą, odwagą. Wyobrażenie takie będzie przedstawiane jako „koń wietrzny” (chijmor), siła wznosząca ku górze, promieniująca na innych, także - pociągająca. Wtedy też pojawia się jednak element siły życia „uspołecznionej”, zwanej bujan - to fortuna i bogactwo nagromadzone jako sieć relacji: przyjaciół, uczynków, bogactwa i potencjalnych przysług. Jest to moment bardzo intensywnego „okiełznania” czy „zaprzęgania" powodzenia, czynienia go obecnym"1.

C. Humphrey, U. Hürelbaatar Fortune in the Wind. An Impersonal Subjectivity, "Social Analysis" 20122 (56), s. 152-167; O. Tangad Scheda po Czyngis Chanie. Demokracja po mongolsku, Trio, Warszawa 2013, s. 105-121.

11 R. Empson The Danger of Excess. Accumulating and Dispersing Fortune in Mongolia, "Social Analysis", 20121 (56), s. 1-12. 
Tę formę powodzenia widać jednak z czasem coraz wyraźniej, samochody, którymi rodziny się poruszają, to bogate, wielkie landy, warte niejednokrotnie więcej niż niewielkie domy, ogrzewane blaszanymi piecykami. Są te samochody często współwłasnością, np. grupy braci, którzy je sobie nieustannie przekazują - to rodzaj charakterystycznego „czasowego posiadania”. Są one też nośnikami prestiżu, ale i świadectwem powodzenia, łutu szczęścia, nakręcania możliwości powodzenia. Dopiero po jakimś czasie widać, że wielki land jest wypełniony współdziałającymi mężczyznami, że tablica rejestracyjna ma szczęśliwy, symetryczny numer (np. 7997) o wartości niemal dorównującej samemu pojazdowi ${ }^{12}$. Dostrzeganie elementów prestiżu i budowania powodzenia, noszenia stroju, tabakiery, inwestowania w konie-championy, kawalkada gnających landów do stóp świętej góry - wszystko staje się nie tylko zrozumiałe, ale po prostu dostrzegalne. To w ten sposób etnograf powoli nabywa nowej kompetencji widzenia bogactwa, powodującego powodzenie i tego, co Mongołowie zwą bujan, siłą związaną z gromadzeniem się ludzi i sztuką nieformalnego działania, gromadzącego innych wokół siebie. Pojawia się w ten sposób pewien specyficzny, żywiołowy, w dużym stopniu nieprzewidywalny mechanizm współdziałania, ma on formę współpracy, nieformalnego dzielenia korzyści i ambicji biznesowych, a jednocześnie jest formą „nakręcania”, nabudowywania zanurzonych w lokalnej kosmologii sił życia i powodzenia.

Po pewnym czasie wyłania się w ten sposób pewien fragment uzyskiwanej wiedzy, uchwyconej w trakcie badań. Jak jednak do tego doszło, że powstała akurat taka właśnie wiedza? Jak powstawała? Można zauważyć, że w tym przypadku jest to bardziej wiedza tworzona za pomocą pewnego rzemiosła widzenia, dostrzegania, wykuwania "pola uwagi" niż za pomocą wypracowanych schematów opisowych, którymi rządzą przede wszystkim reguły tekstu. To wykuwające się rozumienie jest więc źródłem tez logiki opisu kulturowego, ,pod spodem” tego, co tekstowe, kryje się zatem pewna praktyka etnografii rozumiana już jako pewna forma hermeneutyki działania (akcji), interpretacji, która nie wyprowadza wcale swoich reguł interpretacyjnych ze studiów nad tekstami. Można by zatem postawić tezę, że istnieje pewna hermeneutyka wewnątrz ciągu obserwacji, praktyk wychwytywania i pamiętania zjawiających się „faktów” i że tworzy ona w końcu pewną oryginalną, cichą i decydującą o powodzeniu badań ścieżkę, „ścieżkę

12 O. Tangad Kategorie tradycyjnej moralności w życiu społecznym współczesnych Mongołów, kps., IEIAK UW, Warszawa 2015. 
etnograficzną"13. Jest to więc swoiste przedsięwzięcie etnograficzne - proces kierowania i zwracania uwagi, budowania momentów zrozumienia i łańcuch towarzyszących temu notatek, nie jako jedynie zapisywanych słów, ile przede wszystkim zapisywania gęstych, kompleksów, „porcji” pamiętania tzw. headnotes $^{14}$ - przy pisaniu, nagrywaniu, robieniu zdjęć. Aby to pełniej wyjaśnić, posłużę się tu myślą Thorstena Geisera ${ }^{15}$. Zajmuje się on koncepcją wiedzy budowanej poprzez „praktyki czeladnicze”. Czeladnik, pokazuje w swoich analizach Geiser, uczy się od swego nauczyciela podążać za jego ontologicznym horyzontem i tak jak on angażować się w otaczające go środowiska. Dla czeladnika, ucznia - to podążanie jest więc niczym używanie laski służącej do „dotykowego widzenia” przez niewidomego. Laska ta nie jest w tym przypadku przedmiotem - jest raczej sposobem komunikowania się ze światem. Powstaje w ten sposób pewna kompetencja, wiązka doświadczenia, umiejętności, coś co działa i przenosi się dalej w tekst i co jako takie powinno być może mieć nawet status „dzieła”, tak jak przyjmuje go właśnie tekst, pisany esej, dramat czy widowisko.

Writing culture jest tu mimo wszystko jednak wciąż punktem kluczowym. Pojawia się tu wielość skrzypiących piór, „eksperymentalne ewokacje” Tylera, poniechane zostają bezpośrednie referencje do opisywanej rzeczywistości. Stąd antropologia sięgająca do rodzących się znaczeń, często w cielesności i pamięci etnografa, sięga jakby jeszcze wcześniej, ale jednocześnie jest również pogrążona - i nieustannie to odkrywa - w niepewności języka, jego przedwczesności i zarazem spóźnieniu w stosunku do napotykanych doświadczeń. Co więcej, oto okazuje się nagle, że tak naprawdę ta napotykana rzeczywistość kulturowa w dużym stopniu ma taką dynamikę, ma taką autonomię, taką swoją skomplikowaną strukturę, że staje się najważniejsza i może zmienić i przebudować myślenie i całą narrację antropologa. O ile w paradygmacie „czytania kultury” następuje zatem przejście od „gęstej lektury"16 do opisu gęstego (odkrywania zsemityzowanej rzeczywistości), do

13 R. Sanjek On Ethnographic Validity, w: Fieldnotes. The Makings of Anthropology, ed. by R. Sanjek, Cornell University Press, Ithaca-London 1990.

14 Zob. S. Ottenberg Thirty Years of Fieldnotes. Changing Relationship to the Text, w: R. Sanjek, Ithaca and Cornell University Press, London 1990.

Zob. T. Geiser Embodiment, Emotion and Empathy. A Phenomenological Approach to Apprenticeship Learning , Anthropological Theory” 2008 3, s. 310.

16 Zob. J. Tokarska-Bakir Od "gęstego opisu” do une lecture serrée, w: tejże Obraz osobliwy. Hermeneutyczna lektura źródełetnograficznych, Universitas, Kraków 2000, s. 11-17. 
ekstatycznych eksperymentów pisarskich, znoszących odniesienia i wskazujących odmienność powstających narracji, o tyle w przypadku etnografii kierującej się ku temu, co jeszcze przedtekstowe, pojawia się moment, kiedy proces powstawania wiedzy staje się płynny, ucieleśniony, kiedy ciągle przebudowuje się to, co i jak się widzi i postrzega. To moment, kiedy rozpruwa się dotychczasowa percepcja, by następnie zaraz zostać pozszywaną w kontakcie z innymi osobami, przestrzeniami, doświadczeniami" ${ }^{17}$.

Thomas Csordas ${ }^{18}$ pokazał przy tym, że prawdopodobnie to sam Geertz nadmiernie zsemiotyzował idee zapisu działania znaczącego Ricœura, niejako wbrew intencjom samego autora, oraz że antropologowie to za tym ruchem przede wszystkim podążali, interpretując później i „czytając" kultury; jednocześnie sugeruje on, że w samym eseju Ricœura możemy właśnie znaleźć coś, co można by przypisać do rzeczywistości ucieleśnionej i nietekstowej. W antropologicznej sztuce opisu istnieje zatem szansa na nieskończone rozwijanie hermeneutyki działania i tego, co ucieleśnione, co empiryczne; w stronę koncentracji na rzeczach mających charakter zjawiających się „faktów” czy „zdarzeń" - przykładami takich prac mogą być rozwijane od lat monografie i prace Michaela Jacksona $^{19}$, Paula Stollera ${ }^{20}$, Thomasa Csordasa ${ }^{21}$, Kirsten Hastrup ${ }^{22}$, Andrew Irvinga ${ }^{23}$ czy Anne Line Daalsgard ${ }^{24}$. „Kultura - pisze wprost Csor-

17 A. Duranti Husserl, Intersubjectivity, and Anthropology, "Anthropological Theory” 201010 (1-2), S. $16-35$.

18 T. Csordas Introduction: The Body as Representation an Being-in-the World, w: Embodiment and Experience. The Existential Ground of Culture and Self, ed. by T. Csordas, Cambridge 2001, s 11.

19 M. Jackson Paths Toward a Clearing. Radical Empiricism and Ethnographic Inquiry, Indiana University Press, Bloomington 1989; M. Jackson Minima Ethnographica: Intersubjectivity and the Anthropological Project, University of Chicago Press, Chicago 1998; M. Jackson Existential Anthropology. Events, Exigencies, and Effects, Berghahn Books, Oxford 2008.

P. Stoller Sensuous Scholarship, University of Pennsylvania Press, Philadelphia 1997.

T. Csordas Embodiment and Experience. The Existential Ground of Culture and Self, ed. by T. Csordas, Cambridge 2001.

22 K. Hastrup Droga do antropologii. Między doświadczeniem a teoriq, przeł. E. Klekot, Wydawnictwo U), Kraków 2008.

A. Irving The Art of Life and Death: Radical Aesthetics and Ethnographic Practice, HAU Malinowski Monograph Series, University of Chicago Press, Chicago 2016.

24 A.L. Dalsgaard Matters of Life and Longing. Female Sterilisation in Northeast Brasil, Museum Tusculanum Press, Copenhagen 2004. 
das - nie może być poznawana jako przedmiot czy reprezentacja, ale jako ucieleśniony proces percepcji, w którym wszystkie te reprezentacje powstają"25.

\section{Współpoznawanie: nowy paradygmat badań antropologicznych}

Zastanawiający w tym tworzeniu wiedzy opartej na udziale w czyimś doświadczeniu jest sam moment przebudowywania się percepcji. Po dominacji tekstowego, opisowego uchwytywania rzeczywistości, ale i przeciwnie, po odkryciu owej innej, zanurzonej w fenomenologii tradycji rozumienia, również zwartej w opisie etnograficznym, dzieje się następnie coś więcej - pojawia się powrót do wiedzy o współwytwarzaniu pól poznawczych w antropologii. To znów moment na swój sposób niezwykle istotny, ponieważ zawiera w sobie też element namysłu etycznego, odkrycia, że „interpretacja kultur” jest aktem bardzo jednostkowym, egocentrycznym i w istocie (w kontekście odkrywania idei laboratorium i paradygmatu współpracy inspirowanej wytwarzaniem nowych technologii, szczególnie w nurcie Science and Technology Studies) to wyczerpujący się obecnie dla wielu model etnografii. Taka idea etnografii współczesności, z zadaniami badania technologii, przepływów, produkcji i dystrybucji wiedzy, problemu dostępu do wiedzy i w ogóle globalnych presji i nierówności ekonomicznych spowodowała w pewnym momencie konieczność odkrycia współdziałania i w ogóle, jak to ujęli D. Holmes i G. Marcus, „przeformułowanie etnografii”26, czyli wyjścia poza wizję Malinowskiego - poza wizję odosobnionego terenu i samotnego etnografa. Stopniowo pojawiają się wtedy właśnie coraz ciekawsze teorie o współdziałaniu i współwytwarzaniu nowej wiedzy. Tomas Sanchez Criado i Adolfo Estalella w pracy Experimental Collaborations ${ }^{27}$ przedstawili trzy rodzaje metodologii, które wykształciły się w badaniach antropologicznych rozumianych jako współpraca. Pierwszy to formuła obserwacji uczestniczącej, w której badacz uczestniczy w świecie, wchodzi w relacje intymności społecznej, prowadzi rozmowy i wywiady i na ich podstawie stopniowo kształtuje swoją wiedzę.

25 T. Csordas Embodiment and Cultural..., s. 146.

D. Holmes, G. Marcus Przeformułowanie etnografii. Wprowadzenie do antropologii współczesności, w: N.K. Denzin, Y.S. Lincoln Metody badań jakościowych, t. 2, PWN, Warszawa 2009.

27 A. Estalella, T. Sanches Criado Experimental Collaborations. Introduction, w: Experimental Collaborations. Ethnography Through Fieldwork Devices, ed. by A. Estalella, T. Sanches Criado, http:// xcol.org/xcol-book/, (29.08.2016). 
Drugi to sytuacja, kiedy wspólne $\mathrm{z}$ badanymi podmiotami wytwarza się taki opis sytuacji, który będzie głosem politycznym i zaangażowanym, co więcej, czyni się często rozmówców współautorami tekstu. Trzeci, najbardziej rozwijający się obecnie rodzaj współpracy, to jednak sytuacja, w której ludzie, z którymi pracują badacze, zaczynają być rozpoznawani jako podmioty budujące i aranżujące, podobnie jak antropologowie, socjologowie czy artyści, też samą scenę spotkania; to zatem bardziej rodzaj wspólnego eksperymentowania poznawczego, nawet teoretycznego, wokół tego, co jest możliwe, z całą świadomością tego, że antropologiczny rozmówca również konstruuje swoisty przebieg badań, o czym przekonali się Holmes i Marcus w rozmowie ze "sprytniejszym" w kierowaniu rozmową Jeanem Marie Le Penem, w trakcie badań narodzin nacjonalistycznych dyskursów. Mimo wszystko jest to właśnie model sytuacji, w której przyznaje się rozmówcom ich własne zdolności tworzenia wyobraźni społecznej. „Nasze zadanie - piszą Holmes i Marcus - to włączyć w pełni analityczne zdolności i rozpoznania naszych rozmówców i współpracowników w proces definiowania tego, co dla nas istotne"28. Marcus w swoich wcześniejszych pracach związanych z projektem etnografii wielostanowiskowej pokazuje, że kultura i zarazem aktywności twórcze nigdy nie są związane tylko ze środowiskiem społecznym, miejscem, grupą ludzi, że nie można budować jedynie typowo antropologicznego, opisowego charakteru badanego środowiska ${ }^{29}$. Pojawia się tu natomiast przede wszystkim taka sytuacja, w której kultura nie ma cech jakichś zdefiniowanych zasobów, czegoś „gotowego", co można by opisać, mechanicznie, metodycznie tego użyć czy wprost wykorzystać. Jest to raczej moment, kiedy pojawia się konieczność takiej etnografii, która będzie miała formę działania i współdziałania, a zapleczem teoretycznym do przeprowadzenia tego typu badań jest koncepcja „zwrotu działaniowego" w naukach społecznych $^{30}$ (związana też z ideą badawczego „odgrywania i pobudzania

D. Holmes, G. Marcus Collaboration Today and the Re-imagination of the Classic Fieldwork Encounter, "Collaborative Anthropology", 1/2008, s. 86.

29 G. Marcus Ethnography in/of the Word System: The Emergence of Multi-Sited Ethnography, "Annual Review of Anthropology" 1995 No. 24, S. 95-117.

P. Reason, W. Torbet Zwrot działaniowy. Ku transformacyjnej nauce społecznej, w: Badania w działaniu. Pedagogika i antropologia zaangażowane, red. H. Červinkowá, B.D. Gołębniak, Wydawnictwo Naukowe Dolnośląskiej Szkoły Wyższej, Wrocław 2010; zob. też A. Skórzyńska Kto potrzebuje współ-badań? (Participatory) action research jako projekt emancypacji (intelektualistów), „Kultura Współczesna” 2013 2, oraz T.R. Schatzki, K. Knorr-Cetina, E. von Savigny The Practice Turn in Contemporary Theory, Routledge, London-New York 2001. 
kultury"31). W sensie następuje tu właśnie powrót do hermeneutyki działania, w której działanie i eksperymentowanie nie jest dodatkiem do uzyskanej już wiedzy, ale może być wręcz naturalnym środowiskiem jej powstawania. Inspiracje płyną tutaj m.in. z prac Wilfreda Carra ${ }^{32}$, który odwołuje się do greckiego phronesis, pojęcia wiedzy rozgrywającej się w działaniu, a metodologowie action research pokazują, że jest to znacznie bardziej naturalna sytuacja poznawcza, właśnie jako hermeneutyka akcji, a przez to nieustannego testowania i odkształcania wiedzy, niż pozycja dystansu i wyłączenia, pozycja skole, jak to określił Pierre Bourdieu (funkcjonowanie w ramach pewnej swobody czasu i bezpiecznego dystansu do opisywanych wydarzeń) ${ }^{33}$. Co więcej, z etnograficznego i badawczego punktu widzenia przekraczamy w ten sposób ramy typowej, konwencjonalnej obserwacji etnograficznej i przesuwamy się właśnie w stronę eksperymentu.

Polem, w którym w szczególny sposób wykuwa się nowa forma takiej eksperymentalnej etnografii, a właściwie eksperymentalnego współdziałania (experimental collaboration) są paraetnograficzne praktyki artystyczne. O „zwrocie etnograficznym” w sztuce współczesnej pisał w latach 9o. Hal Foster w znanym eseju Artysta jako etnograf ${ }^{34}$, rozpoznając też wtedy już jednak pewną obecną tych praktykach poznawczą i etyczną pułapkę. To, czego potrzebuje artysta, pisał Foster, to wyjście na zewnątrz, w stronę nie-swoich doświadczeń, w stronę odmiennego i peryferyjnego świata społecznego, aby tam znajdować moce buntu, oporu i subwersji. To wtedy zatem szczególnie rozwija się praktykowanie wyjścia do światów spoza mainstreamu, artworldu, w których działania artysty nabierają swoistej ciężkości. Artysta, pokazuje Foster, działa w ten sposób trochę niczym etnograf, działa wśród doświadczeń grup podporządkowanych, grup wykluczonych, w miejscach społecznych napięć, doświadczając wyobcowania i egzotyzacji siebie samego (self-othering). Podobnie jak surrealiści i etnografowie z lat 20. i 30. XX wieku, prymitywiści i poszukiwacze realizmu życia, usiłują oni dotrzeć w miejsce

K.B. Alexander Etnografia performatywna. Odgrywanie i pobudzanie kultury, przeł. Ł. Marciniak, w: Metody badań jakościowych, t. 1, red. N.K. Denzin, Y.S. Lincoln, PWN, Warszawa 2009.

W. Carr Filozofia, metodologia i badania w działaniu, w: Badania w działaniu. Pedagogika i antropologia zaangażowane, red. H. Červinkowá, B.D. Gołębniak, Wydawnictwo Naukowe Dolnośląskiej Szkoły Wyższej, Wrocław 2010. 
kulturowych peryferii, a stamtąd pozwolić spojrzeć w oczy obiegom dominującym, „galeriom”, publicystom”, „nauczycielom" - i zmusić tym samym zachodnie, „późne”, dostatnie społeczeństwa do spojrzenia w oczy samym sobie. W każdym razie sztuka społeczna niewątpliwe nabrała rozpędu, sięgając do tego, co społeczne, peryferyjne, zawiązując artystyczne działania partycypacyjne, a kolejni teoretycy awangardy w sztuce i antropologii mówią już o wyraźnym „zwrocie społecznym” w sztuce współczesnej, przy czym być może jest to nawet pewien instytucjonalno-polityczny koniunkturalizm, próba nadążania za kolejnym, zdecydowanie centralnym, porywającym strumieniem uwierzytelniającym po prostu sztukę, która już teraz, ktoś mógłby powiedzieć, aby żyć - musi być społeczna.

Jest to jednak też dla antropologii i dla nowej humanistyki moment wyjątkowo ważny. Pojawia się tutaj działanie artystyczne właśnie jako forma eksperymentalnego współtworzenia, zmieniającego poznanie humanistyczne. Pojawi się wiele relacji i pokrewieństw między praktykowaniem sztuki awangardowej i praktykowaniem antropologii, o czym piszą np. Chris Wright i Arnd Schneider ${ }^{35}$, wskazując na głębokie połączenia (deeper affinities) obu aktywności oraz na wcale nieoczywiste „rozbrojenie” antropologii kultury z narzędzi sztuki (obecne chociażby w pracach Bronisława Malinowskiego, pozbawionych - co prawda z powodów także pozamerytorycznych - narzędzi sztuki, w tym przypadku - sztuki Witkacego ${ }^{36}$ ). Takie głębokie połączenia mogą być odnajdowane na wielu poziomach, sztuka, tak jak antropologia, może stać się ośrodkiem reinterpretowania rzeczywistości. Roger Sansi w opracowaniu Anthropology, Art and the Gift ${ }^{37}$ ostrożnie wskazuje na pewną odpowiedniość wydarzenia, jakim były eksperymenty Writing Culture, z eksperymentami artystycznymi. Jest to bowiem sytuacja, kiedy wiedza jest wytwarzana w eksperymencie, poza reprezentacjami procesów i zdarzeń społecznych; jest ona bardziej już formą wywoływania możliwych, złożonych światów i jak niegdyś składała się z literackich eksperymentów, tak teraz coraz bardziej składa się z montowanej, wytwarzanej i pobudzanej interakcji, relacji, kultury. To zatem, po pierwsze, moment, kiedy sztuka i antropologia „pracują" na rzeczywistości - i to dlatego, że inspiracją dla działań Art and Anthropology, Berg, Oxford 2006, s. 2. 
artystycznych stały się obszary pracy antropologa ${ }^{38}$. Po drugie jednak, artysta sięga tam, gdzie sięgali tradycyjnie etnografowie. Artyści jednak, co zaznaczał Joseph Kosuth ${ }^{39}$, wchodzą w naturalny sposób w pozycję walczących, zaangażowanych podmiotów, działających w pewnej reakcji, w kontrze do zastanych form kulturowych, w których przeżywają swe życie i od których są zależni (Roger Sansi pisze, że czują oni presję tego, co kulturowe ${ }^{40}$ ). Jest to sytuacja, która w kontekście polskim formuje w ogóle pewien punkt wyjścia: współczesna sztuka zaangażowana działa często $\mathrm{w}$ taki sposób, by podporządkować się efektowi realności działania - by wytwarzać wyraźną zmianę społeczną, tak jak dzieje się w działaniach Artura Żmijewskiego. Żmijewski w swoim manifeście „Sztuki społecznie stosowanej”" pisze wyraźnie, że artystę stać po prostu na pewną polityczną dojrzałość, że można domagać się tego, by tworzyć nowe warunki życia społecznego, sięgać ku temu, co skuteczne, nawet ku - pewnej władzy.

Taka forma zmiany społecznej i polityczna skuteczność nie jest jednak, jak uważam, w wyraźny sposób jakimś otwarciem nowego pola poznawczego, które mogłoby się pojawić na pograniczu sztuki i antropologii. Aby taka forma powstała, chodziłoby tutaj bowiem bardziej o takie sytuacje, w których wykształca się nowa realność życia społecznego (także nowa wyobraźnia społeczna), nieobecna wcześniej, wywołana, ale która w pły w a też zwrotnie na twórcę działań i tego, kto „odgrywa i pobudza” kulturę. Byłaby to zatem sytuacja współpracy w „trzecim trybie” - a więc w sytuacji, kiedy doświadczenia i rzeczywistość innych ludzi są obecne, aktualne i kiedy ludzie mają możliwości zwrotnego działania, tzn. też - kształtowania i współkształtowania interpretacji tego świata i miejsca, w którym jesteśmy. Jest to już bardziej obopólne „odkształcanie” świata, po obydwu stronach spotkania, a więc, coś co Johaness Fabian ${ }^{42}$ nazywa jednoczasowością (coevalness) w poznaniu antropologicznym.

\footnotetext{
38 Tamże, s. 20.
}

39 J. Kosuth Artist as Anthropologist (extracts) [1975], w: The Everyday, Documents of Contemporary Art, ed. by S. Johnstone, The MIT Press, Cambridge 2006. R. Sansi Anthropology, Art and the Gift,s. 20-21. A. Żmijewski Stosowane sztuki społeczne , „Krytyka Polityczna” 2007 nr 11-12.

42 J. Fabian Time and the Other. How Anthropology makes its Object, Columbia University Press, New York 1983. 
Nie jest to jednak spotkanie ani jedno- ani nawet dwubiegunowe, nawet sugerujące pewien dialog. Etnograficzny performens to raczej forma działania - to jednoczasowe przekształcenie pola uwagi, wiedzy, poznania, władzy. Pojawia się coś w rodzaju „kulturowego cyklotronu”43 , etnograficzne doświadczenie jest punktem wyjścia, ale jednocześnie powstaje zupełnie nowe pole poznawcze, to zatem ryzyko "przywrócenia”, „skompletowania” doświadczenia, można by dopowiedzieć za Victorem Turnerem ${ }^{44}$. Znakomitym przykładem jest w tym przypadku praca etnograficzno-artystyczna Doroty Ogrodzkiej „Panny Młode”45, w której powstają gęste, międzyludzkie interakcje, uruchomione tylko poprzez sytuację parateatralną. Etnografka, artystka zaczęła pracę od rozmów o doświadczeniu ślubu na wsi pod Szydłowcem: kobiety wspólnie oglądały albumy ślubne, suknie, które wisiały w szafie, wreszcie wspólnie wpadły na pomysł, żeby założyć jeszcze raz suknie ślubne i przejść w paradzie "panien młodych" przez wieś. Chodziło zatem m.in. o to, aby odzyskać moment wyjścia do ludzi, moment ceremonii weselnej i ślubu, skorzystać z własnego repertuaru biograficznego. Moment przejścia „panien młodych" przez wieś w sukniach ślubnych, które bardzo często były już zniszczone, ze zrobionymi wcześniej kwiatami z bibuły, z tortem weselnym był wyraźnie widowiskowy, performatywny, w całym tego słowa znaczeniu. Czerpał on przy tym z własnego repertuaru biograficznego i tworzył nową grupę wewnątrz wiejskiej społeczności, aż wreszcie uobecnił je jako pewną osobną zbiorowość. Wyposażenie biograficzne, kulturowe czy społeczne, po które sięgnięto, było w ten sposób punktem wyjścia (często też trudne doświadczenia: historie rozwodu, samotności, niezrozumienia), ale to nowa scena działania była tu najważniejsza, wytwarzana we wspólnej pracy. Cała sytuacja powstawała nie tyle w cieniu projektu i osoby, która całą tę sytuację reżyseruje, ale samo to spotkanie i interakcja spowodowały dopiero to, co się dalej wydarzyło. W ten sposób zamiast „partycypacji” i „integracji" pojawiło się niepewne spotkanie, o charakterze właściwie bardziej dramatu społecznego, który dostrzegał w etnografii jeszcze Victor Turner

43 Zob. T. Rakowski Etnografia/animacja/sztuka. Wprowadzenie, w: Etnografia/animacja/sztuka. Nierozpoznane wymiary rozwoju kulturalnego, red. T. Rakowski, Narodowe Centrum Kultury, Warszawa 2013.

Zob. V. Turner Od rytuału do teatru. Powaga zabawy, przeł. M. i J. Dziekanowie, Oficyna Wydawnicza "Volumen", Warszawa, s. 150-151.

45 Zob. D. Ogrodzka Powracająca panna młoda. Performatywne (od)tworzenie tożsamości i przestrzeni, w: Etnografia/animacja/sztuka. Nierozpoznane wymiary rozwoju kulturalnego. 
(przywołuje on np. scenę z badań Malinowskiego, w której jeden z młodych ludzi wchodzi na czubek drzewa i grozi samobójczym skokiem, natomiast zebrani wokół niego matrylinearni krewni jego nieżyjącego ojca chcą go wypędzić z wioski) ${ }^{46}$. Pochód „panien młodych” miał zatem w sobie element czegoś nieprzewidywalnego: spotkania i zarazem urządzenia „puszczanego w ruch", w którym i dla etnografki, i dla mieszkanek Broniowa pojawiały się różne nowe i jednocześnie bardzo osobiste znaczenia. Znaczenia sukien ślubnych, kwiatów, pochodu, tortu, którym obdarowywani są przechodnie, sięgają w tym projekcie oczywiście do lokalnego „układu kultury”, do kulturowego wyposażenia mieszkańców wsi. Sięgają w tym samym momencie jednak także do znaczeń budowanych w projekcie performensu i etnograficzno-dramaturgicznej „pracy na rekwizytach”. To, co jednak tutaj najbardziej istotne, to niespodziewane narodziny pewnego trzeciego układu, trzeciej sfery znaczeń, a właściwie czegoś, co Erika Fisher-Lichte określała mianem "emergencji znaczenia" ${ }^{\text {"77. }}$.

W ten sposób pojawia się sfera etnograficznego spotkania, w której działają siły lokujące się już właściwie poza intencjami i dążeniami samego badacza, artysty czy etnografa - i kiedy wytworzona sytuacja (np. projektu artystycznego) zaczyna na nowo kształtować sposób widzenia i pozwala na zaistnienie nowego pola. Jest to jednak też taka sytuacja, w której nie mamy do czynienia z żadnym silnym, skutecznym działaniem politycznym, „sztuką społecznie stosowaną" i jej mierzalnymi efektami. Mamy tu raczej do czynienia z nowym polem współpracy i eksperymentalnego współdziałania, a jeśli powstają efekty tych działań, to mają one charakter często niespodziewanych, choć nieraz bardzo realnych "nie-mechanicznych” konsekwencji działania. W tym miejscu można pójść jeszcze krok dalej, w uznanie narodzin pewnej innej, wzbudzanej w interakcji podmiotowości społecznej. Jest to forma „wprawiania w ruch” życia społecznego, co pozwala na wytworzenie alternatywnych sposobów działania i stworzenia, jak pisał Nicolas Bourriaud (w przedmowie do Estetyki relacyjnej ${ }^{48}$ ) alternatywnego stołu montażowego, by - nawet w formie prototypu - przeprogramować to, co społeczne, i z powrotem zsubiektywizować zarówno sztukę, jak i życie codzienne; są

46 V. Turner Od rytuału do teatru..., s. 153.

47 E. Fisher-Lichte Estetyka performatywności, przeł. M. Borowski, M. Sugiera, Księgarnia Akademicka, Kraków 2008, s. 225, 230-232.

48 N. Bourriaud Estetyka relacyjna, przeł. Ł Białkowski, MOCAK, Kraków 2012, s. 26. 
to właśnie te „ośrodki”, które - jakby chciał Bourriaud - mogą stawiać opór "powszechnej, czysto ideologicznej bierności”.

Pojawia się jednak tutaj też coś innego, jeszcze inna pozycja podmiotu: jest to, podobnie jak w rytualnych zabiegach wywoływania stanu liminalnego u Turnera, sytuacja podmiotu o d a n tro p o l o g i z o w a n e go, tj. pozbawionego przypisania kulturowego i społecznego, o czym pisze od kilku lat Nigel Rapport i co rozwija w swoich ostatnich książkach ${ }^{49}$. Ta domyślna pozycja przekroczenia wielu ról społecznych, pozycja, w której pojawia się przemienność i w związku z tym pewna potencjalna nieograniczona zdolność do ironicznej i krytycznej liminalności, do bycia kimś nieprzypisanym, każdym z nas, Anyone. Co istotne, to przejście dokonuje się w tym przypadku i w tym ujęciu przede wszystkim właśnie wewnątrz indywidualnych aktów każdego z nas, „kogokolwiek”, Anyone, a nie „na zewnątrz” jednostki - w antropologicznej demaskacji czy w uspołecznionych widowiskach. „Nie było nigdy - przywołam tu po raz kolejny Victora Turnera - żadnego niewinnego, nieświadomego dzikiego żyjącego w czasie bezrefleksyjnej i instynktownej harmonii. My, ludzie, jesteśmy wszyscy i zawsze wyrafinowani, świadomi, zdolni do śmiechu z naszych własnych instytucji"50.

\section{Wytwarzanie rzeczywistości: zwrot ontologiczny i produkcja tego, co etnograficzne}

Problem polega jednak wciąż na tym, że można mieć wrażenie, iż antropologia jest zastosowana $w$ tym przypadku do analizy i interpretacji mimo wszystko „wywołanej" $i$ „sztucznie wytworzonej” sytuacji. Pojawia się tu więc znów pewna świadomość modelowania i tworzenia tego, co należy do wiedzy etnograficznej i tego, że jest to, co jest, nie tyle odczytywane czy rekonstruowane, ile konstruowane i wywoływane. Rzeczywiście, jest to w pewnym sensie powrót do eksperymentalnych strategii autorów Writing Culture, obnażających siły poetyki i polityki w poznaniu antropologicznym, jednak tutaj pojawia się ten moment jakby jeszcze wcześniej, już w trakcie narodzin

49 N. Rapport Człowiek nieprzypisany, jakikolwiek, Anyone. O uznanie podmiotu postkulturowego i kosmopolitycznego, przeł. T. Rakowski, J.S. Wasilewski, w: Colloquia Anthropologica, red. M. Buchowski, A. Bentkowski, Wydawnictwo Nauka i Innowacje, Poznań 2014, zob. też: T. Rakowski Nieustająca zdolność do działania. Nigela Rapporta antropologia wolności, w: Colloquia Anthropologica. 
rzeczywistości społecznej. W pewnym sensie można mówić tu o produkowaniu alternatywnych ontologii społecznych, co jest o tyle istotne, że po załamaniu się wielkiego eksperymentu tekstowego, to właśnie tzw. zwrot ontologiczny jest kolejnym punktem orientacyjnym w antropologicznych próbach określenia wiedzy o kulturze. Studia zainicjowane przez Eduarda Viveirosa de Castro ${ }^{51}$ (perspektywizm w antropologii) i prace rozwijane przez badaczy takich jak Martin Holbraad czy Morten Axel Pedersen ugruntowują nowe podejście, wykluczające w dużym stopniu problemy epistemologiczne, traktując je jako swego rodzaju "nakładkę" na silne i różne ontologie wytwarzane przez poszczególne środowiska i grupy. Ludzie żyją w różnych rzeczywistościach, w sensie ontologicznym, a narzędzia antropologiczne, np. dotyczące rzeczy w innych kulturach, nie tyle mówią coś o tych rzeczach (np. o pewnym proszku używanym w wyroczniach kultu Ifa na Kubie, wyposażającym wróżbitę w „działającą moc"52), ile nakazują myśleć poprzez nie i za pomocą nich samych, prowadząc w stronę innych ontologii. „Koncepty są realne, a to co realne jest konceptualne" ${ }^{53}$, piszą przedstawiciele tego zwrotu, znosząc niejako granice między tym, co materialne, i tym, co pojęciowe, co jednak nie tyle jest pewnym uproszczeniem dawnych i klasycznych problemów filozoficznych, ile wskazaniem pewnego impasu poznawczego koniecznego dla uchwycenia nowego języka: przejścia w stronę refleksywnego wywoływania inności, pracy konceptualnej i, wreszcie, jak ostatnio wyraźnie zaproponował to Martin Holbraad ${ }^{54}$, eksperymentowania (np. parateatralnego), budowania takiego narzędzia, które wywoła rzeczywistość jako formę tego, co traktowane i co praktykowane może być jako rzeczywiste.

Wiele łączy ten kierunek z produkcją artystyczną, a szczególnie z takimi eksperymentami w polu sztuki, które odnoszą się do wywoływania wielości ontologii, też w sensie poznawczym. Na różne sposoby pojawia się tam

51 E. Viveiros de Castro Perspectival anthropology and the method of controlled equivocation, "Tipitií: Journal of the Society for the Anthropology of Lowland South America" 2004 No. 2 (1), S. 2-20.

52 M. Holbraad The power of powder: Multiplicity and motion in the divinatory cosmology of Cuban Ifá (orMana, again), w: A. Henare, M. Holbraad, S. Wastell (eds.) Thinking Through Things: Theorising Artifacts Ethnographically, Routledge, London 2007.

53 A. Henare, M. Holbraad, S. Wastell (eds.) Thinking Through Things: Theorising Artifacts Ethnographically, s. 9.

54 M. Holbraad Three ontological turn-ons, https://www.youtube.com/watch?v=c-SQBe-V7Jw (29.09.2016). 
bowiem też moment produkowania i wywoływania pewnej innej, alternatywnej rzeczywistości, a która następnie okazuje się trudna do zanegowania, „działająca”. Przestrzeń eksperymentów etnograficzno-artystycznych, zakładających pewne możliwe, konceptualne ontologie, można by więc wstępnie określić jako pracę wytwarzania scenerii tego, co etnograficzne. W tego typu działaniach to, co konceptualne, poprzedza niejako to, co etnograficzne. Za działaniem, za konceptem działania powstaje dopiero pewna wywoływana czy produkowana rzeczywistość, co Nikolai Ssorin-Chaikov ${ }^{55}$ nazwał praktyką "konceptualizmu etnograficznego"; to etnograficznie konstruowane urządzenie wywołuje tutaj to, co społeczne, co produkuje interakcje, relacje, wiąże ze sobą różnych ludzi i różne środowiska. W pewnym sensie przypominają te zabiegi mechaniczną formę pułapki, która na wiele sposobów staje się nową metaforą w antropologii. Badacze pogranicza sztuki i antropologii, podążając m.in. za Alfredem Gellem, wskazują na urządzenia konstruujące zdolność do budowania scenariuszy społecznych, budujących „dramatyczną więź" między twórcą i „użytkownikami” wytworzonej sytuacji ${ }^{56}$. By jednak wskazać na konkretny przypadek, odwołam się tutaj do „pułapki na rzeczywistość”, jaką był wyraźnie projekt „Skupu Łez” Alicji Rogalskiej i Łukasza Surowca ${ }^{57}$. Powstało tu urządzenie czy narzędzie służące do wytwarzania nowej sytuacji i właściwie - do wytwarzania nowego środowiska interakcji. „Skup łez" jako osobny lokal powstał na ulicy 1 maja w Lublinie, w okolicy pełnej komisów, lombardów, punktów oferujących ubezpieczenia na życie (i od nieszczęśliwych wypadków), punktów z „chwilówkami” i agencjami Providenta, sklepów z bronią, fluidami, e-papierosami. Przypominał nieco recepcję gabinetu odnowy biologicznej, trochę bank lub parabank, na oknach wyklejony został napis podobny do tych reklamujących zakup obligacji, złota czy do założenia rachunku. Zachęca do skorzystania ze skupu:

55 N. Ssorin-Chaikov Ethnographic Conceptualism. An Introduction, "Laboratorium" 20135 (2), s. 5-18.

56 A. Gell Vogel's Net. Traps as Artworks and Artworks as Traps, "Journal of Material Culture" 1996 1, S. 15-38, s. 27, R. Sansi Anthropology, Art and the Gift,. s. 51, E. Rossal Tropy i pułapki etnografii twórczej i otwierajqcej, „Prace Etnograficzne UJ” 2017 nr 1 (złożony do druku); kategorii pułapki W antropologii sztuki poświęcony jest ponadto rozdział pracy doktorskiej Weroniki Plińskiej, zob. W. Plińska Działania animacyjne w społecznościach lokalnych. Perspektywa antropologii sztuki, praca doktorska, IKP UW, Warszawa 2016, s. 69-77.

57 Zob. T. Rakowski Społeczna droga donikąd. Skup Łez jako zbiór "pytań właściwych", w: Katalog z lat 2013.2014, Pracownia Sztuki Zaangażowanej Społecznie "Rewiry", Lublin 2014. Zob. też J. Prus Skup Łez, w: Katalog z lat... 
„100 pln za 3 ml łez*”, a poniżej objaśnienie do znaku*: „wypłakanych na miejscu". Z czasem zaczęły się tam pojawiać kolejki chętnych, a w samym skupie ludzie płakali, wpatrując się w lustra, przykładając pod oczy cebulę, sztyfty z olejkami eterycznymi, dzwoniąc do byłych partnerów czy słuchając zasmucającej muzyki, wracając do swoich myśli. Jak się okazało, powstała w ten sposób zupełnie od nowa sytuacja, w której artyści, ludzie, ale też badacze zmuszeni byli bardzo starannie dobierać słowa. Kontekst wypłakiwania łez, liczonych w pojemnościach, zmuszał bowiem do budowania nowych sformułowań i do nowych ujęć wobec rzeczy tak dwuznacznej, tak nierealnej, jak konkretna praca za pomocą łez i emocji. Otworzyła się jednak wtedy też droga do pewnej etnograficznej wiedzy o okolicznych problemach, o życiu przybywających tam ludzi, o nieszczęściach, o próbie przetrwania na przyczółku na ulicy przy dworcu, z wynajmowanymi tanio i zamienianymi mieszkaniami, poddaszami, punktami usługowymi. Eksperymentowanie polega więc tutaj na wstępnym „uchwyceniu” czy wręcz „wydobyciu” czegoś charakterystycznego dla terenu społeczno-kulturowego i następnie "podszycia się" pod niego (udawania drobnego, chwilowego, trochę "dziwacznego" biznesu), po chwili jednak sama sytuacja skupu wywołuje już nową, "pochodną" rzeczywistość, której się dotyka, która staje się środowiskiem nowego rozumienia tego, co społeczne, i która przekracza intencje działających - wywołuje jakby eksperymentalnie wielość światów etnograficznych, nawet w postaci płaczących obok siebie ludzi, grup, całych rodzin.

Ta nowa, eksperymentalna rzeczywistość jest więc tutaj pewnym punktem dojścia, Pojawia się jednak w ten sposób pewna wyraźna zmiana i przebudowanie pola antropologii, a poprzez to wskazanie w ogóle też pewnej zmiany w humanistyce. Jest to bowiem sytuacja, która powraca do impasu pracy tekstowej, by wyjść w stronę alternatywnego montażu, wywoływania nowych form, namacalnego poznawania różnic w [społecznych] ontologiach. Można jednak również zauważyć, że zwraca się także w stronę tego, co rysuje się jako możliwe, co może zostać współprojektowane, a więc w stronę przyszłości jako punktu orientacyjnego, modulującego to, co możliwe. To forma wiedzy, o której bardziej jako o czynności „robienia” niż jakiejś gotowej, zakumulowanej wiedzy pisze Tim Ingold - przy czym przyszłość jest tutaj jakby wyobrażonym punktem spinającym jej nici. Jest to zwrot na swój sposób radykalny. Zamiast „zakumulowanej przeszłości”, która była zwykle stawką w poznaniu antropologicznym, tożsamości, kultury, pamięci, wszelkich pól „odkrywanych” w kulturze, mamy tu zatem bardziej współwytwarzaną 
i współprzewidywaną przyszłość, odwołującą się do praktyk takich jak co-design w ujęciu Thomasa Bindera (z zespołem) z pracy Rehearsing the Future ${ }^{58}$ czy Experimental Collaboration ${ }^{59}$ w ujęciu Adolfo Estalelli i Thomasa Sanchez-Criado. Ta przemiana pola, improwizacja, współwytwarzanie warunków rozumienia, to jednak wciąż próba przejścia w stronę czynności i czasownikowej formuły kultury, a więc też nieodwołalnego przejścia ku czemuś, co zakotwiczone jest w wyobrażanej i „uprawianej” przeszłości i sięga ku temu, co możliwe. Poprzez zapośredniczenie, eksperyment, współtworzenie uzyskać można zatem nowe ontologie i nowe semantyki (w pewnym sensie to nawet działania na rzecz „sztuki deziluzyjnej” Stefana Themersona, pragnącej uwolnić sensy słów i czynności od przypadkowych, nagromadzonych, „propagandowych" użyć).

Czasownikowy wymiar tego, co się pojawi w eksperymencie czy nawet w ogóle w kulturze - na co zwracał uwagę Ryszard Nycz ${ }^{60}$ - skoncentrowany jest na czynności, a więc właściwe jest też stanem określającym pewną wyjątkowość tego, co ludzkie, i to właśnie za pomocą czasownika. Tim Ingold wskazuje wręcz w swoich najnowszych tekstach, że właściwie należałoby

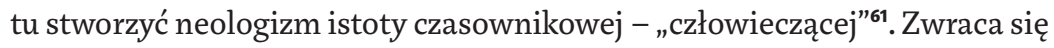
tu do poety, mistyka i teologa z XIII stulecia, Ramona Llulla (żyjącego na Majorce) i przywołuje jego pojęcie zwierzęcia człowieczącego, animal hominicans, przy czym tłumacze angielscy zwracają tu uwagę nie tyle na czynność „uczłowieczenia” (humanify), wyciśnięcia wzoru na rzeczywistości, ile „uczłowieczenia" (homininize) nieustanne nabudowywanie tego, co ludzkie, a więc tak naprawdę nieustanne zwracanie się w stronę przyszłości ${ }^{62}$. „Człowieczyć” jest czasownikiem, można by więc powtórzyć za Timem Ingoldem. To w taką stronę ponownie zmierza nowa antropologia, która ramię w ramię z eksperymentami artystycznymi produkuje to, co przed nami i co zarazem

58 J. Halse, E. Brandt, B. Clark, T. Binder (eds.) Rehearsing the Future, The Danish Design School Press, Copenhagen 2010.

59 A. Estalella, T. Sanches Criado Experimental Collaborations...

60 Zob. R. Nycz Kultura jako czasownik, wykład, https://www.youtube.com/watch?v=PpiAuOxWfzg (29.09.2016).

61 T. Ingold "Człowieczyć" to czasownik, przeł. E. Klekot, w: Colloquia Anthropologica, red. M. Buchowski, A. Bentkowski, Wydawnictwo Nauka i Innowacje, Poznań 2014.

62 Tamże, s. 528-529. 
zyskuje status niepewnej, otwartej i trudnej, choć coraz bardziej możliwej rzeczywistości.

\section{Abstract}

\section{Tomasz Rakowski}

UNIVERSITY OF WARSAW

Ethnography and Artistic Experiments: Emerging Research Areas in Anthropology

To what extent is it possible, in the humanities, to frame research in terms of pre-textual and non-textual ways of reading? Following the textual turn, which is mostly associated with semiotics as well as descriptive and interpretive orientations, ethnography is returning to more source-based and immediate endeavours. This is, however, a return to very demanding and uncertain methods, which are only now being examined, unearthed and tested. They emerged against the backdrop of the ontological turn in contemporary anthropology and the practical and action-based turn in the social sciences. In the research team that I direct, we are developing a definition of a creative ethnography that has the potential to create openings; although linked to the anthropology of art, it is also able to propose new languages and ways of grasping cultural facts. Thus I aim to outline a possible path for anthropology, where its unique'developmental cycle' parallels the ontological turn and the action-based turn. A particularly important role in this development falls to the artistic experiment as a way of creating a new field of research and of reaching towards unforeseeable research situations.

\section{Keywords}

art, experiment, collaboration, experience, ontology, action 